$(26,7 \%)$ patients were treated with biological therapy and $22(21.0 \%)$ of them were taking tocilizumab. Patients were assessed using a combination of clinical, laboratory and radiological evaluation before and after Tocilizumab therapy. The demographic and clinical characteristics of the patients, the pre-tocilizumab and end of the follow-up acute phase values (Erythrocyte sedimentation rate (ESR), C-reactive protein (CRP)), visual analogue scales (VAS) (Pain, Fatigue, Patient Global), and concomitant therapies were recorded. Other clinical, imaging and laboratory results of the TA patients were obtained from hospital files. The comparative imaging (Computed Tomography and Magnetic Resonance Imaging) results of the patients just before the Tocilizumab therapy and during follow-up were recorded from the hospital data system.

Results: Twenty-two patients ( $86.4 \%$ female) were included in to the analysis The median (minimum-maximum) age of the patients was $40^{24-63}$ years and the median disease duration (from diagnosis) was $48^{12-168}$ months. Before tocilizumab therapy; cyclophosphamide (8 patients $(36.4 \%$ ), conventional immunosuppressives (21 patients, 95.4\%) and TNFi (7 patients, 31.8\%) were used in addition to corticosteroid therapy. Main indications for tocilizumab therapy was as follows; radiological progression in 9 patients (acute phase was normal in 2 of them), acute phase elevation in 8 patients ( 4 of them radiologically stable, 4 of them had no radiologic evaluation), physician's decision and clinical symptoms in 3 patients (acute phase normal; 2 of them radiologically stable, one had no radiologic evaluation), in two patients tocilizumab therapy was started out of our centre and data before tocilizumab was not available. Fifteen patients (median follow-up time $15^{3-42}$ months) were evaluated for response to tocilizumab treatment. There was a significant decrease in ESR, CRP, and VAS-patient-global of patients after tocilizumab therapy; median (min-max) ESR (26 $6^{5-119}$ vs. 3 (2-49) mm/s, p=0.02), CRP (39.8 (2.4-149.0) vs. $7.9(0-92,9) \mathrm{mg} / \mathrm{L}, \mathrm{p}=0,017)$, VAS-patient-global $(50(0-90)$ vs. $30(0-60)$, $\mathrm{p}=0,027$ ), respectively. Total of 9 patients had follow-up imaging; 8 of them was radiologically stable and regression was seen in one patient (figure 1).

Table 1:

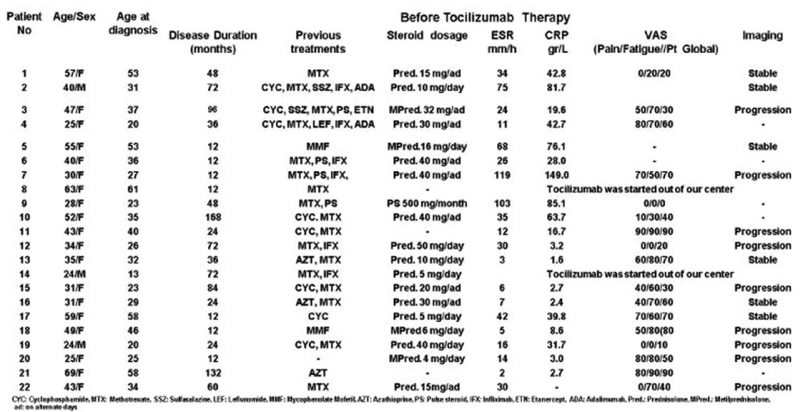

Conclusions: The use of biological therapies in more than a quarter of TA patients suggests that the role of conventional therapies in TA is limited. Although imaging modalities and acute phase elevations are the main factors in the decision of change in treatment, presence of symptoms and physician opinion are also important. Significant response was obtained with the treatment of tocilizumab.

Disclosure of Interest: None declared

DOI: 10.1136/annrheumdis-2018-eular.6756

\section{THU0453 EFFICACY OF AB INITIO OR VERY EARLY INTRODUCTION OF IMMUNOSUPPRESSIVE THERAPY IN GIANT CELL ARTERITIS: A MULTICENTER RETROSPECTIVE OBSERVATIONAL STUDY}

L. Quartuccio ${ }^{1}$, E. Cavallaro ${ }^{1}$, F. Angelotti ${ }^{2}$, R. Capecchi ${ }^{2}$, G. Vitiello $^{3}$, D. Cammelli ${ }^{3}$, A. Tavoni ${ }^{2}$, S. De Vita ${ }^{1} .{ }^{1}$ Department of Medical Area, Rheumatology Clinic, Udine Academic Hospital "Santa Maria della Misericordia", Udine; ${ }^{2}$ Department of Internal Medicine, Clinic of Immunology, Pisa; ${ }^{3}$ Experimental and Clinical Medicine Department, School of Allergy and Clinical Immunology, University of Florence, Florence, Italy

Background: Glucocorticoids (GC) remain the mainstay of treatment of giant cell arteritis (GCA). However, relapses occur in up to $50 \%$ of patients when GC are tapered and prolonged courses of GC are associated with serious side effects. In this setting, the outcome is frequently determined by GC-related adverse events
(AEs). Thus, several studies have been conducted on the effectiveness of a GCsparing immunosuppressive therapy (IT), with conflicting results.

Objectives: To evaluate the effectiveness of IT in a series of GCA patients, in: 1 ) reducing the risk of GCA relapse; 2) lowering the exposure to GC therapy; 3) minimising the occurrence of steroid-induced AEs.

Methods: We performed a multicenter retrospective observational study including 69 patients $(75,4 \%$ females; mean age \pm SD $68,7 \pm 7,8$ y; median follow-up time 40 months [range 26-65]) diagnosed with GCA, all receiving an adjunctive IT given ab initio (71\%) or within 3 months from the start of GC. All but 17 patients (with extracranic involvement) fulfilled the GCA ACR classification criteria. Risk of first relapse of GCA, GC exposure and main AEs were retrospectively analysed. Results were compared with those reported in other studies, all characterised by a lower use of IT.

Results: all patients received GC plus IT: methotrexate up to $20 \mathrm{mg} /$ week in 63 patients, cyclophosphamide in 22 , tocilizumab in 12 . In the follow-up, a firs relapse of GCA occurred in $14(20,3 \%)$ of patients. The rates of first relapse at 12 , 24,36 and 48 weeks were $4,3 \%, 11,6 \%, 15,9 \%$ and $15,9 \%$, respectively, in com parison with rates of $24,3 \%, 41,6 \%, 61 \%, 64,9 \%$, respectively, in the GC monotherapy arm in the meta-analysis by Mahr, ${ }^{1}$ where similar data were available. The median daily prednisone dose at beginning was $50 \mathrm{mg}$, and decreased to $10 \mathrm{mg}$ at 3 months and to $5 \mathrm{mg}$ at 6 months. The median time required to reduce prednisone to $7.5 \mathrm{mg} /$ day and $5 \mathrm{mg} /$ was 3 and 5 months respectively (vs. 6.5 and 7.5 months in series by Proven, ${ }^{2}$ where similar data were available). In our cohort, lower cumulative GC use was accompanied by a reduction of AEs, without further toxicity (tab.1).

\begin{tabular}{|c|c|c|c|c|c|c|}
\hline & Present work & $\begin{array}{l}\text { Proven } \\
20032\end{array}$ & $\begin{array}{r}\text { Mahr } \\
20071\end{array}$ & $\begin{array}{l}\text { Souza } \\
20143\end{array}$ & $\begin{array}{r}\text { Alba } \\
20144\end{array}$ & Labarca 20165 \\
\hline $\begin{array}{l}\text { Number of } \\
\text { patients }\end{array}$ & 69 & 120 & 77 & 45 & 106 & 286 \\
\hline$\%$ use of IT & $100 \%$ & $2 \%$ & $0 \%$ & $55,6 \%$ & $14,2 \%$ & $0 \%$ \\
\hline $\begin{array}{l}\text { Follow up, } \\
\text { months }\end{array}$ & 40 & 120 & 13,7 & 54,9 & 93,6 & 61,2 \\
\hline $\begin{array}{l}\text { Fragility } \\
\text { fractures }\end{array}$ & $11,6 \%$ & $38 \%$ & $8 \%$ & NA & NA & $27 \%$ \\
\hline Diabetes & $4.3 \%$ & $9 \%$ & $12 \%$ & $33,4 \%$ & $8,5 \%$ & NA \\
\hline Hypertension & $8.7 \%$ & $22 \%$ & NA & $66,7 \%$ & $51 \%$ & $1,7 \%$ \\
\hline Infections & $\begin{array}{c}10,1 \%(2,9 \% \\
\text { needing } \\
\text { hospitalisation) }\end{array}$ & $31 \%$ & NA & $23 \%$ & NA & $\begin{array}{l}17 \% \text { (all needing } \\
\text { hospitalisation) }\end{array}$ \\
\hline
\end{tabular}

Conclusions: The use of IT ab initio or very early in the treatment of GCA appears to be effective and safe, lowering the risk of relapses, reducing $\mathrm{GC}$ dose and the rate of GC-related AEs. Therefore, the present data support the early introduction of IT in the treatment of GCA.

\section{REFERENCES :}

[1] Mahr AD, et al. Arthritis Rheum 2007;56(8):2789-97.

[2] Proven A, et al. Arthritis Rheum 2003 49(5):703-8.

[3] Souza AW, Okamoto KY, Abrantes F, et al. Clinics (Sao Paulo) 2013;68:317-322.

[4] Alba MA, et al. Medicine (Baltimore) 2014;93( ${ }^{5}: 194-201$.

[5] Labarca C, et al. Rheumatology (Oxford) 2016;55(2:347-56.

Disclosure of Interest: None declared

DOI: 10.1136/annrheumdis-2018-eular.3794

\section{THU0454 INCREASED FDG UPTAKE OF THE MUSCLES IN POLYMYALGIA RHEUMATICA (PMR)}

M.A. Cimmino ${ }^{1}$, N. Vecchiola ${ }^{1}$, M. Bauckneht ${ }^{2}$, D. Camellino ${ }^{3}$, S. Morbelli ${ }^{2}$ S. Paolino ${ }^{1}$, M. Cutolo ${ }^{1}$, G. Sambuceti ${ }^{2}$. ${ }^{1}$ Department of Internal Medicine, University of Genova; ${ }^{2}$ Division of Nuclear Medicine, Università di Genova; ${ }^{3}$ Autoimmunology Laboratory, University of Genova, Genova, Italy

Background: PMR is an inflammatory disease affecting the shoulder and pelvic girdles of elderly patients. Its causes, development mechanisms and anatomical targets of inflammatory damage are still elusive. Synovitis, vasculitis, and bursitis have all been demonstrated in PMR but data on muscles are scanty.

Objectives: Our study evaluated muscular uptake at FDG-PET/CT in patients with PMR.

Methods: Fifty patients with PMR diagnosed according to Bird et al criteria and 50 age- and sex-matched control patients without inflammatory disorders, who underwent FDG-PET/CT to rule out malignancy, were studied. Standard FDG- 